\title{
ELECTRON MICROSCOPY OF LUMINAL EPITHELIUM SEPARATED BY BEADS IN THE PSEUDOPREGNANT MOUSE UTERUS
}

\author{
ANNE MaLAREN AND O. NILSSON \\ Institute of Animal Genetics, Edinburgh, Scotland, and \\ Department of Anatomy, S752 20 Uppsala, Sweden
}

(Received 18th December 1970)

The process of implantation in the mouse is accompanied by striking changes in the ultrastructure of the uterine epithelium. During the progesteronedominated pre-attachment stage, the luminal epithelium is bordered by a fringe of regular microvilli, and a small gap separates the epithelial surface from the blastocyst or from the epithelium lining the other side of the lumen. Under the influence of oestrogen, the luminal epithelium enters on the attachment stage. The microvilli become more irregular and finally flatten out altogether, and the gap between opposing luminal surfaces, or between luminal surface and blastocyst, shrinks to 150 to $200 \AA$ (Nilsson, 1966; Potts, 1966; Reinius, 1967). This change occurs equally in the unstimulated pseudopregnant uterus, and must therefore be considered a sensitization rather than a decidual effect (McLaren, 1969). A similar modification of the epithelial surface has been reported for the rat (Mayer \& Nilsson, 1966; Potts \& Psychoyos, 1967), the hamster (Young, Whicher \& Potts, 1968; Nilsson, 1970) and the guinea-pig (Nilsson, 1970), but does not occur in the rabbit and the mink (Nilsson, 1970).

In both pregnant and pseudopregnant animals, the apposition of the cell surfaces always involves a structural change of the luminal membrane. To determine whether the change of the cell membranes depends on the cell-tocell contact, or whether it develops autonomously as a result of some factor intrinsic to the epithelium, plastic beads were transferred to the pseudopregnant mouse uterus, and the ultrastructure of the epithelium-bead interface was examined. Such beads do not normally elicit a decidual response (McLaren, 1968) or impede a simultaneous pregnancy.

Twenty-two pseudopregnant mice of the randomly bred $Q$ strain were used, $2 \frac{1}{2}$ or $3 \frac{1}{2}$ days after mating with a vasectomized male. Six to ten beads suspended in phosphate-buffered saline were transferred to one uterine horn, and saline alone was injected into the other uterine horn. The day after the operation, the mice were despatched by air from Edinburgh to Uppsala.

Three types of bead were used. (1) Spherical beads of acrylic polymer MG (Diakon, ICI), about $100 \mu \mathrm{m}$ in diameter. These carry low levels of watersoluble materials adsorbed on to the surface during the manufacturing process. One of the contaminants that could be present is known to have surface irritant properties. (2) Beads as above, but thoroughly rinsed in distilled water. (3) Spherical beads, about $100 \mu \mathrm{m}$ in diameter, of polymethylmethacrylate, 
prepared with a non-toxic initiator, in such a way that any surface contaminant should be non-irritant and only present at very low levels. These beads were exhaustively washed with distilled water before drying.

The mice were prepared by an aortic perfusion with $2.5 \%$ glutaraldehyde in phosphate buffer, $\mathrm{pH} 7 \cdot 2,5$ to 7 days after mating. The uterine horns containing beads and some control horns were cut into pieces 2 to $3 \mathrm{~mm}$ long, post-fixed in a buffered solution of osmium tetroxide, and Epon-embedded for longitudinal sectioning. The specimens were serially sectioned on a Porter Blum microtome and when beads appeared, the blocks were trimmed for sectioning for electron microscopy.

Six sites with Type-1 beads, one site with Type- 2 beads, and three sites with Type-3 beads were examined. The sites examined were distributed among the animals, and only in a few cases were two beads from one mouse studied. The beads were found by light microscopy to lie tightly surrounded by the luminal epithelium (Pl. 1, Fig. 1). Electron microscopy revealed that they were separated from the luminal surface of the epithelium by a secretion. The amount of the secretion varied, being highest in Type-1 beads ( 3 to $4 \mu \mathrm{m}$ ) and lowest in Type-3 beads $(0.2$ to $0.4 \mu \mathrm{m})$.

The luminal membrane of the surface epithelium had an irregular course around the bead (Pl. 1, Fig. 2). The outline of the luminal membrane was similar to that of the membrane when it was apposed not to a bead but to an epithelial cell lining the other side of the lumen (PI. 1, Fig. 3). In this normal situation, lesser amounts of secretion occurred irregularly between the apposing epithelial surfaces. The structural character of the luminal membrane during the attachment stage was different from that during the pre-attachment stage when the cell surfaces possessed regular microvilli.

The cellular ultrastructure of the epithelium adjacent to the beads did not differ markedly from that of the epithelium at non-adjacent sites, when examined $5 \frac{1}{2}$ or $6 \frac{1}{2}$ days after mating. At $7 \frac{1}{2}$ days, however, a decrease in cell height was noticed at one bead site.

Thus, the structural change which the luminal membrane normally undergoes at the time of blastocyst attachment is seen also where the epithelium is in contact with a bead and its secretion, just as it is where the epithelium is in contact with trophoblast or with the apposing epithelial surface. This structural change could result either from a pathological transformation of the cells, which was caused by the beads, or from a hormonal influence on the cells.

\section{EXPLANATION OF PLATE I}

Fig. 1. A plastic bead (Type 1) in the uterine lumen of a pseudopregnant mouse, 6 days after mating. The uterine lumen in the vicinity of the bead is nearly closed. Light microscopy. $\times 450$.

Fig. 2. Luminal surface of the uterine epithelium at a bead site in a pseudopregnant mouse, 6 days after mating. The peripheral part of the plastic bead (Type 1) is seen as empty zone to the right (b). The left of this zone follows a rim of secretion (s), separating the bead from the epithelium (e). The epithelial surface has an irregular course. $\times 30,000$.

Fig. 3. Luminal surfaces of apposing uterine epithelium at an area away from the bead sites in a pseudopregnant mouse, 7 days after mating. A minor amount of secretion appears between the surfaces. The luminal membranes have an irregular course similar to that at the bead sites. $\times 30,000$. 

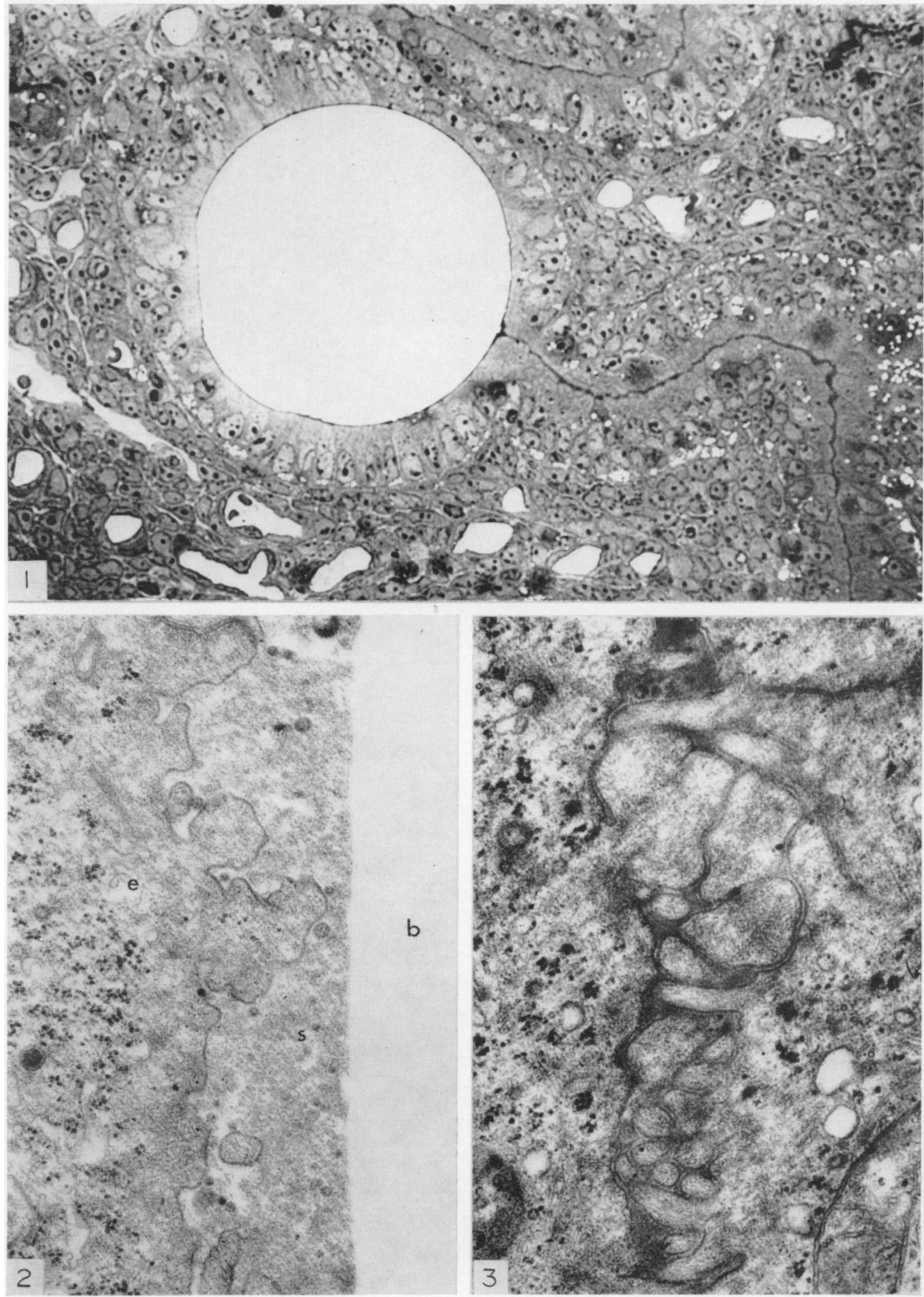

(Facing p. 380) 
Since, at the time of blastocyst attachment, no ultrastructural difference was observed between cells at the bead sites and those elsewhere, we regard the second possibility as the more plausible one. We therefore conclude that the structural change of the luminal membrane depends upon an intrinsic factor, and does not require contact with another cell surface.

The irritant qualities of the beads, especially those manufactured by the original process, are evident from the amount of secretion which they cause. Since the beads do not normally elicit a decidual reaction, one may conclude that an irritant stimulus of this type does not induce deciduogenesis.

Financial support from the Ford Foundation to A.McL. and from the Swedish Medical Research Council (Project Nr B71-12X-70) to O.N. is acknowledged. We are grateful to the Steel and Moulding Powders Research Group, ICI Plastic Division, for preparing the polymethylmethacrylate beads for us.

\section{REFERENCES}

MAYER, G. \& NiLsson, O. (1966) Normal and retarded nidation in the rat: an ultrastructural study of the uterine epithelium and of the blastocyst. Proc. Vth Wld Congr. Fert. Steril., Excerpta med. Int. Congr. Ser. 133.

McLaren, A. (1968) Can beads stimulate a decidual response in the mouse uterus? F. Reprod. Fert. $15,313$.

MaLAREN, A. (1969) Stimulus and response during early pregnancy in the mouse. Nature, Lond. 221, 739.

NILsson, O. (1966) Estrogen-induced increase of adhesiveness in uterine epithelium of mouse and rat. Expl Cell Res. 43, 239.

NrLsson, O. (1970) Some ultrastructural aspects of ovo-implantation. In: Ovo-implantation, Human Gonadotropins and Prolactin, p. 52. Eds. P. O. Hubinont, F. Leroy, G. Robyn and P. Leleux. Karger, Basel.

Ports, M. (1966) The attachment phase of ovoimplantation. Am. 7. Obstet. Gynec. 96, 1122.

Potrs, M. \& Psychoyos, A. (1967) Evolution de l'ultrastructure des relations ovoendométriales sous l'influence de l'oestrogène, chez la ratte en retard expérimental de nidation. C.r. hebd. Séanc. Acad. Sci., Paris, 264, 370.

ReInius, S. (1967) Ultrastructure of blastocyst attachment in the mouse. Z. Zellforsch. mikrosk. Anat. 77, 257.

Young, M. P., Whicher, J. T. \& PotTs, D. M. (1968) The ultrastructure of implantation in the golden hamster. F. Embryol. exp. Morph. 19, 341. 